\title{
Drug Review: Fosfomycin-A Rarely used but more Practical Approach for Urinary Tract Infections
}

\author{
${ }^{1}$ Prabhat Agrawal, ${ }^{2}$ Ruchika Garg, ${ }^{3}$ Sangeeta Yadav, ${ }^{4}$ Omkar Singh
}

\begin{abstract}
In this current era of resistance, treating urinary tract infections (UTIs) on outpatient department (OPD) basis has become cumbersome. Resistance has dramatically increased for cotrimoxazole, levofloxacin, ciprofloxacin and nitrofurantoin in past few decades. Intravenous drugs increase the cost of treatment and patient may need hospitalization. We searched and analyzed the literature and found fosfomycin to be better alternative in resistant UTI as resistance to this drug is low and is cost-effective in comparison to available intravenous drugs.
\end{abstract}

Keywords: Fosfomycin, Monurol, Resistant urinary tract infection.

How to cite this article: Agrawal P, Garg R, Yadav S, Singh O. Drug Review: Fosfomycin-A Rarely used but more Practical Approach for Urinary Tract Infections. J South Asian Feder Obst Gynae 2015;7(2):68-70.

Source of support: Nil

Conflict of interest: None

Date of received: 21 March 2015

Date of acceptance: 31 March 2015

Date of publication: August 2015

\section{INTRODUCTION}

Fosfomycin is derived from phosphonic acid and acts by inhibiting cell wall synthesis by inhibiting peptidoglycan assembly. ${ }^{1,2}$ Fosfomycin is a broad spectrum antibiotic active against Gram-positive and Gram-negative organisms. In urinary tract infections (UTIs), drug has been found to be very useful and resistance has not emerged yet. When compared to other potential treatments, it has been found to be safer, more cost-effective with lesser contraindications. It is available in the market under the trade name Monurol costing around ₹ 200.

\footnotetext{
${ }^{1,2}$ Assistant Professor, ${ }^{3,4}$ Junior Resident

${ }^{1,4}$ Department of Medicine, SN Medical College, Agra, Uttar Pradesh, India

${ }^{2}$ Department of Obstetrics and Gynecology, SN Medical College, Agra, Uttar Pradesh, India

${ }^{3}$ Department of Pharmacology, LLRM Medical College, Meerut Uttar Pradesh, India

Corresponding Author: Sangeeta Yadav, Junior Resident Department of Pharmacology, LLRM Medical College, Meerut Uttar Pradesh, India, e-mail: y.sangeeta87@gmail.com
}

\section{SPECTRUM AND PHARMACOKINETICS}

It is active against more than 90\% strains of Escherichia coli, Serratia marcescens, Citrobacter diversus, Klebsiella oxytoca, Klebsiella pneumonia, Enterobacter cloacae, Proteus mirabilis, Pseudomonas aeruginosa, Proteus vulgaris, Providencia rettgeri, Enterococcus faecium and Enterococcus faecalis including vancomycin resistant enterococci and methicillin resistant Staphylococcus aureus as shown in various in vitro and clinical studies. ${ }^{3}$ After oral administration, it is rapidly absorbed with bioavailability of 30 to $37 \%{ }^{4}$ Route of elimination is mainly through kidneys by glomerular filtration with excretion as unchanged drug. ${ }^{4}$ Peak serum concentration of drug is reached within 4 hours of 3 gm dose.

\section{RESISTANCE}

Resistance to fosfomycin is mainly chromosomal, though cases of plasmid mediated resistance have been described. ${ }^{5,6}$ Chromosomal resistance occurs due to mutations that interfere with transport systems required for fosfomycin uptake resulting in reduced intracellular concentrations of the drug. ${ }^{2}$ However, these mutations are uncommon and not associated with resistance to other agents. The dosing and frequency of fosfomycin has been described in Table 1.

\section{SIDE EFFECTS}

Most frequently reported adverse events occurring in $>1 \%$ of the study population regardless of drug relationship were: diarrhea, headache, vaginitis, nausea, rhinitis, back pain, pharyngitis, dizziness in decreasing order of frequency and incidence of such side effects is comparable to other commonly used drugs.

\section{METHODOLOGY}

We reviewed various literature and databases including PubMed, Copernicus, IndMED and Google Scholar and analyzed them in reference to the present clinical scenario.

\section{REVIEW OF LITERATURE}

Stein GE et al (1999) conducted a double blind randomized trial and compared fosfomycin 3 gm orally with 
Drug Review: Fosfomycin-A Rarely used but more Practical Approach for Urinary Tract Infections

Table 1: The dosing and frequency schedule of fosfomycin ${ }^{7,8}$

\begin{tabular}{|c|c|c|c|c|c|}
\hline \multicolumn{4}{|c|}{ Patients $\geq 15$ years } & \multirow{2}{*}{$\begin{array}{l}\text { Children }<15 \text { years } \\
(\geq 50 \mathrm{ml} / \mathrm{min})\end{array}$} & \multirow{2}{*}{$\begin{array}{l}\text { Children } \leq 1 \text { year } \\
(\mathrm{CrCl} \geq 50 \mathrm{ml} / \mathrm{min})\end{array}$} \\
\hline Infection & $\mathrm{CrCl} \geq 50 \mathrm{ml} / \mathrm{min}$ & $\mathrm{CrCl} 10-50 \mathrm{ml} / \mathrm{min}$ & $\mathrm{CrCl}<10 \mathrm{ml} / \mathrm{min}$ & & \\
\hline $\begin{array}{l}\text { Uncomplicated } \\
\text { cystitis }\end{array}$ & $3 \mathrm{gm}$ oral $\times 1$ dose & $\begin{array}{l}3 \text { gm sachet oral } x \\
1 \text { dose }\end{array}$ & $\begin{array}{l}3 \text { gm sachet oral } x \\
1 \text { dose }\end{array}$ & $\begin{array}{l}2 \text { gm sachet oral } x \\
1 \text { dose }\end{array}$ & $\begin{array}{l}1 \text { gm sachet oral } x \\
1 \text { dose }\end{array}$ \\
\hline Complicated cystitis & $\begin{array}{l}3 \text { gm oral every } \\
2 \text { days for } 7-21 \text { days }\end{array}$ & $\begin{array}{l}3 \text { gm oral every } \\
3 \text { days for } 7-21 \text { days }\end{array}$ & $\begin{array}{l}3 \text { gm oral every } \\
3 \text { days for } 7-21 \text { days }\end{array}$ & $\begin{array}{l}2 \text { gm oral every } \\
2 \text { days for } 7-21 \text { days }\end{array}$ & $\begin{array}{l}1 \mathrm{gm} \text { oral every } \\
2 \text { days for } 7-21 \text { days }\end{array}$ \\
\hline
\end{tabular}

Renal dysfunction decreases renal excretion (concentration) and, if patient is on hemodialysis, it should be given after hemodialysis. Drug is to be given with 1 glass cool water. Alternate dosing of $3 \mathrm{gm}$ oral every 2 days for 7 to 14 days may be offered to children 12 to 14 years of age with $\mathrm{CrCl} \geq 50 \mathrm{ml} /$ minute

Table 2: Susceptibility to ESBL producing E. coli to other antibiotics

\begin{tabular}{|c|c|c|c|c|c|c|c|}
\hline \multirow[t]{2}{*}{$\begin{array}{l}\text { Total no. of E. coli } \\
\text { from urine }\end{array}$} & \multirow[t]{2}{*}{$\begin{array}{l}\text { No. of ESBL } \\
\text { isolates (\%) }\end{array}$} & \multicolumn{6}{|c|}{$\begin{array}{c}\text { Number of ESBL-producing E. coli } \\
\text { isolates susceptible to (\%) }\end{array}$} \\
\hline & & FOS & ERT & $\mathrm{NF}$ & TMP/SMX & GM & $\mathrm{CP}$ \\
\hline 6076 & 100 & 97 & 66 & 94 & 27 & 78 & 22 \\
\hline
\end{tabular}

FOS: Fosfomycin; ERT: Ertapenem; NF: Nitrofurantoin; TMP/SMX: Trimethoprim/sulfamethoxazole; GM: Gentamicin; CP: Ciprofloxacin

Nitrofurantoin $100 \mathrm{mg}$ PO BD for 7 days. A total number of 749 patients with uncomplicated urinary tract infections (UTIs) were included in the study and it was found that $94 \%$ of isolates were susceptible to fosfomycin as compared to $83 \%$ for nitrofurantoin and adverse events were not different between the two treatment groups (5.3\% for fosfomycin and 5.6\% for nitrofurantoin), and hence concluded that fosfomycin presents a reasonable alternative above all when antimicrobial resistance and patient's allergy precludes the application of first line agents for UTI. ${ }^{9}$

Crocchiolo P et al 1990 included 73 ambulatory nonpregnant women with uncomplicated UTIs and a randomized study of fosfomycin 3 gm vs TMP/SMX 160/800q 12 hour for 3 days was done. Thirty-six were evaluated; 19 were treated with fosfomycin and 17 with TMP/SMX. Bacteriological success after 4 weeks of follow-up was evaluated as such fosfomycin: cure in $17(89 \%)$, and failure in $2(11 \%)$ whereas TMP/SMX: cure in $13(76 \%)$, and failure in $4(24 \%)$. And, hence, it was concluded that fosfomycin had higher sustained bacteriologic cure compared to TMP/ SMX at 4 weeks after treatment completion. ${ }^{10}$

Bozkurt $\mathrm{O}$ et al 2008 compared the efficacy of fosfomycin $3 \mathrm{gm} \times 1$ dose to ciprofloxacin $500 \mathrm{mg}$ PO q 12 hours for 3 days in a double-blind randomized controlled trial of 100 adult nonpregnant women with uncomplicated UTI. ${ }^{11}$ Fifty patients received fosfomycin and 50 ciprofloxacin. Clinical cure among patients who received fosfomycin was 48 out of 50 patients $(96 \%)$ as compared to 47 of 50 patients ( $94 \%$ ) in the ciprofloxacin group. Authors concluded that in treatment of uncomplicated UTI in women, fosfomycin single dose was as efficacious as ciprofloxacin with better tolerability. ${ }^{11}$

Falagas ME et al (2010) conducted a meta-analysis of 27 randomized controlled trials comparing fosfomycin with other antibiotics in treatement of cystistis, with regard to its therapeutic efficacy and relative safety. ${ }^{8}$ In trials involving nonpregnant females; fosfomycin $3 \mathrm{gm}$ single dose was compared to Quinolones (norfloxacin, ciprofloxacin and ofloxacin), trimethoprim, trimethoprim/ sulfamethoxazole, B-lactams (cephalexin and amoxicillin) and nitrofurantoin. In the mixed group studies (nonpregnant and male patients), fosfomycin was compared to norfloxacin, netilmicin or amikacin, and amoxicillin/ clavulanate. In studies of pregnant women, fosfomycin was compared to B-lactams (amoxicillin/clavulanate and ceftibuten) and nitrofurantoin. Fosfomycin showed comparable efficacy for the treatment of patients with cystitis and may provide a valuable alternative option for the treatment of cystitis in nonpregnant and pregnant women, elderly and pediatric patients. ${ }^{8}$

Auer S et al (2010) evaluated in vitro susceptibility of E. coli isolates to select antibiotics. ${ }^{12}$ One hundred extended-specturm $\beta$-lactamases (ESBL) positive E. coli from ambulatory patients with confirmed UTI collected were included in the study. Susceptibility to ESBL producing E. coli to other antibiotics as described in Table 2.

Based on these in vitro susceptibility results, fosfomycin, nitrofurantoin and pivemecillinam could be considered as treatment options for UTI. Extended-spectrum $\beta$-lactamases producing E. coli exhibited excellent in vitro susceptibility to fosfomycin. Other studies have also reported similar high susceptibilities of ESBL-producing E. coli to fosfomycin.

Escherichia coli isolates that produce CTX-M ESBLs have emerged as a serious cause of urinary tract infections (UTIs) in the community. The study by Prakash et al showed that approximately $90 \%$ of urinary CTX-M ESBLproducing isolates were susceptible to the combination of cefdinir plus amoxicillin-clavulanate and to fosfomycin. One hundred percent of isolates were susceptible to ertapenem. Nitrofurantoin was active against $73.9 \%$ of isolates, while only $10.9 \%$ and $4.3 \%$ were susceptible to doxycycline and ciprofloxacin respectively. ${ }^{13}$ 
Allerberger $\mathrm{F}$ et al 1999 demonstrated that based on study susceptibility breakpoints, the MICs of fosfomycin for most VRE isolates were in the intermediate range, yielding an MIC 50 of $32 \mathrm{mg} / \mathrm{l}$ and an MIC 90 of $64 \mathrm{mg} / \mathrm{l}^{14}$

Perri MB et al 2002 evaluated in vitro activity of fosfomycin against 75 clinical isolates of VRE 52 isolates were E. faecium and 23 isolates were E. faecalis. All VRE faecalis isolates were susceptible to fosfomycin. However, only 35 out of 52 (67\%) VRE faecium isolates were fully susceptible to fosfomycin and 16 isolates (31\%) showed intermediate susceptibility $(\mathrm{MIC}=128 \mathrm{mg} / \mathrm{l}) .{ }^{15}$

In an earlier study by Shrestha NK et al (2003) consecutive clinical isolates of VRE faecium (40 blood and 35 urine isolates) over 1 year were tested for susceptibility to linezolid, quinupristin/dalfopristin, fosfomycin and nitrofurantoin using the Etest. All isolates were susceptible to Linezolid. Fosfomycin and quinupristin/dalfopristin had good in vitro activity against VRE faecium, approaching $100 \%$; susceptibility to nitrofurantoin was lower. They concluded that fosfomycin is a useful alternative to linezolid and quinupristin/dalfopristin particularly in treating UTIs due to VRE strains in certain clinical situations, thus ameliorating resistance emergence among Enterococcus spp. to these agents. ${ }^{16}$

\section{CONCLUSION}

The convenience of a single-dose regimen, broad range of activity proven in vitro and in vivo, and minimal propensity for promoting resistant pathogens make fosfomycin an attractive regimen for the treatment of complicated and uncomplicated cystitis. Based on available evidence, the clinical efficacy of fosfomycin was comparable to first line agents for UTI.

\section{ADVANTAGES OF FOSFOMYCIN}

- Single dose regimen.

- Can be given in patients with compromised renal function.

- Low cost of therapy.

- Availability of oral drug with efficacy comparable to IV options.

\section{SUGGESTED REASONABLE USES}

- Empiric treatment of uncomplicated cystitis (nitrofurantoin and TMP-SMX are also potential options).

- Complicated cystitis when other oral options are not available.

- Due to limited systemic absorption, fosfomycin should not be used for pyelonephritis.

- If persistence or reappearance of bacteriuria occurs after treatment with fosfomycin, repeat testing for sensitivity should be performed and another agents be considered as resistance can develop after treatment.

\section{REFERENCES}

1. Kahan FM, Kahan JS, Cassidy PJ, Kropp H. The mechanism of action of fosfomycin (phosphonomycin). Ann NY Acad Sci 1974 May 10;235(0):364-386.

2. Monurol Package Insert. St. Louis: Forest Laboratories, Inc.; 1997.

3. Popovic M, Steinort D, Pillai S, Joukhadar C. Fosfomycin: an old, new friend. Eur J Clin Microbiol Infect Dis 2010 Feb;29(2): 127-142.

4. Bergan T. Degree of absorption, pharmacokinetics of fosfomycin trometamol and duration of urinary antibacterial activity. Infection 1990;18(Suppl 2):S65-69.

5. Arca P, Rico M, Brana AF, et al. Formation of an adduct between fosfomycin and glutathione: a new mechanism of antibiotic resistance in bacteria. Antimicrob Agents Chemother 1988 Oct;32(10):1552-1556.

6. Etienne J, Gerbaud G, Courvalin P, et al. Plasmid-mediated resistance to fosfomycin in staphylococcus epidermidis. FEMS Microbiol Lett 1989 Oct;52(1-2):133-137.

7. Pham PA, Bartlett JG. Fosfomycin. Available at: http:// hopkins-abxguide.org/antibiotics/antibacterial/misc/fosfomycin Accessed 2/10/11.

8. Falagas ME, Vouloumanou EK, Togias AG, et al. Fosfomycin versus other antibiotics for the treatment of cystitis: a meta-analysis of randomized controlled trials. J Antimicrob Chemother 2010 Sep;65(9):1862-1877.

9. Stein GE. Comparison of single-dose fosfomycin and a 7-day course of nitrofurantoin in female patients with uncomplicated urinary tract infection. Clin Ther 1999 Nov;21(11): 1864-1872.

10. Crocchiolo P. Single-dose fosfomycin trometamol versus multiple-dose cotrimoxazole in the treatment of lower urinary tract infections in general practice. Multicenter Group of General Practitioners. Chemotherapy 1990;36(Suppl 1):37-40.

11. Bozkurt O, Kara C, Akarsu S, et al. Comparison efficacy of single dose fosfomycin with ciprofloxacin in the treatment of urinary tract infection in symptomatic women. Turk Uroloji Dergisi 2008;34(3):360-362.

12. Auer S, Wojna A, Hell M. Oral treatment options for ambulatory patients with urinary tract infections caused by extended-spectrum-beta-lactamase-producing Escherichia coli. Antimicrob Agents Chemother 2010 Sep;54(9):4006-4008.

13. Prakash V, Lewis JS 2nd, Herrera ML, et al. Oral and parenteral therapeutic options for outpatient urinary infections caused by Enterobacteriaceae producing CTX-M extendedspectrum beta-lactamases. Antimicrob Agents Chemother 2009 Mar;53(3):1278-1280.

14. Allerberger F, Klare I. In-vitro activity of fosfomycin against vancomycin-resistant enterococci. J Antimicrob Chemother 1999 Feb;43(2):211-217.

15. Perri MB, Hershberger E, Ionescu M, et al. In vitro susceptibility of vancomycin-resistant enterococci (VRE) to fosfomycin. Diagn Microbiol Infect Dis 2002 Apr;42(4):269-271.

16. Shrestha NK, Chua JD, Tuohy MJ, et al. Antimicrobial susceptibility of vancomycin-resistant Enterococcus faecium: potential utility of fosfomycin. Scand J Infect Dis 2003;35(1): 12-14. 